\title{
High-Yield Synthesis of Silver Nanoparticles by Precipitation in a High-Aqueous Phase Content Reverse Microemulsion
}

\author{
Y. D. Sosa, ${ }^{1}$ M. Rabelero, ${ }^{2}$ M. E. Treviño, ${ }^{1}$ H. Saade, ${ }^{1}$ and R. G. López ${ }^{1}$ \\ ${ }^{1}$ Centro de Investigación en Química Aplicada, Boul. Ing. Enrique Reyna No. 140, Saltillo, Coahuila, 25253, Mexico \\ ${ }^{2}$ Departamento de Ingeniería Química, Universidad de Guadalajara, Boul. M. García Barragán No. 1451, \\ Guadalajara, Jalisco, 44430, Mexico
}

Correspondence should be addressed to R. G. López, glopez@ciqa.mx

Received 28 August 2009; Revised 13 November 2009; Accepted 8 January 2010

Academic Editor: Michael Wong

Copyright (C) 2010 Y. D. Sosa et al. This is an open access article distributed under the Creative Commons Attribution License, which permits unrestricted use, distribution, and reproduction in any medium, provided the original work is properly cited.

\begin{abstract}
Silver nanoparticles were precipitated at $70^{\circ} \mathrm{C}$ in a reverse microemulsion containing a high concentration of $0.5 \mathrm{M}$ silver nitrate aqueous solution, toluene as organic phase, and a mixture of surfactants sodium bis (2-ethylhexyl) sulfosuccinate/sodium dodecyl sulfate $(2 / 1, w / w)$. Nanoparticles were characterized by X-ray diffraction, atomic absorption spectroscopy, and high-resolution transmission electron microscopy. In spite of the high-water/surfactant molar ratio and concentration of silver nitrate solution used in this study, characterizations demonstrated that nanoparticles were silver crystals (purity $>99 \%$ ) with $8.6-8.8 \mathrm{~nm}$ in average diameter and $2.9-4.7 \mathrm{~nm}$ in standard deviation. It is proposed that slow dosing rate of aqueous solution of precipitating agent and the small molecular volume of toluene attenuated both particle aggregation and polydispersity widening. Experimental yield of silver nanoparticles obtained in this study was much higher than theoretical yields calculated from available data in the literature on preparation of silver nanoparticles in reverse microemulsions.
\end{abstract}

\section{Introduction}

The synthesis and characterization of nanoparticles have attracted increasing attention in recent years because particles with sizes in the range of few nanometers behave differently than larger, nonnanoscale particles. According to specialized literature [1], the two main reasons for this change in behavior are an increase in the surface area/mass ratio and the dominance of quantum size effect as particle size decreases. Such increase in the surface area/mass ratio will result in a corresponding increase in chemical reactivity. On the other hand, as the size of particles is reduced $(\leq 10 \mathrm{~nm})$, quantum effects can significantly change optical, magnetic, or electrical properties. Silver nanoparticles are especially interesting due to their applications such as surface enhanced Raman spectroscopy [2,3], catalysis $[4,5]$, and bactericidal agents $[6,7]$. Among the methods for preparing silver nanoparticles, precipitation in reverse microemulsion is one that usually allows to prepare particles with diameters smaller than $10 \mathrm{~nm}$ and narrow particle size distributions [818]. The intense research on synthesis of silver nanoparticles by this method has led to a detailed knowledge of the effect of some of the most important variables on the mechanism of particle formation. Nevertheless, in these reports authors used low-water contents (usually $<10 \mathrm{wt} . \%$ in microemulsions), which lead to very low yields of silver nanoparticles. In spite of that those yields are not reported, calculations of theoretical values from available data in those documents allow knowing that theoretical yields range from near 0.1 $[8,9,11,14,15]$ to $0.4[10] \mathrm{g}$ per $100 \mathrm{~g}$ of reaction mixture.

Here we report the precipitation and isolation of silver nanoparticles from a high-(water/silver nitrate)-content reverse microemulsion stabilized with the mixture of surfactants sodium bis (2-ethylhexyl) sulfosuccinate (AOT)/sodium dodecyl sulfate (SDS) $(2 / 1, \mathrm{w} / \mathrm{w})$ with toluene as organic phase, upon slow titration with an aqueous sodium borohydride $\left(\mathrm{NaBH}_{4}\right)$ solution as precipitating agent.

\section{Materials and Methods}

2.1. Materials. Silver nitrate $\left(\mathrm{AgNO}_{3}\right)(>99 \%), \mathrm{NaBH}_{4}$ ( $>98 \%)$, SDS ( $>98.5 \%)$, toluene ( $>99.8 \%$ ) from Aldrich, and AOT $(>96 \%)$ from Fluka were used as received. Water was of tridistilled deionized grade. 


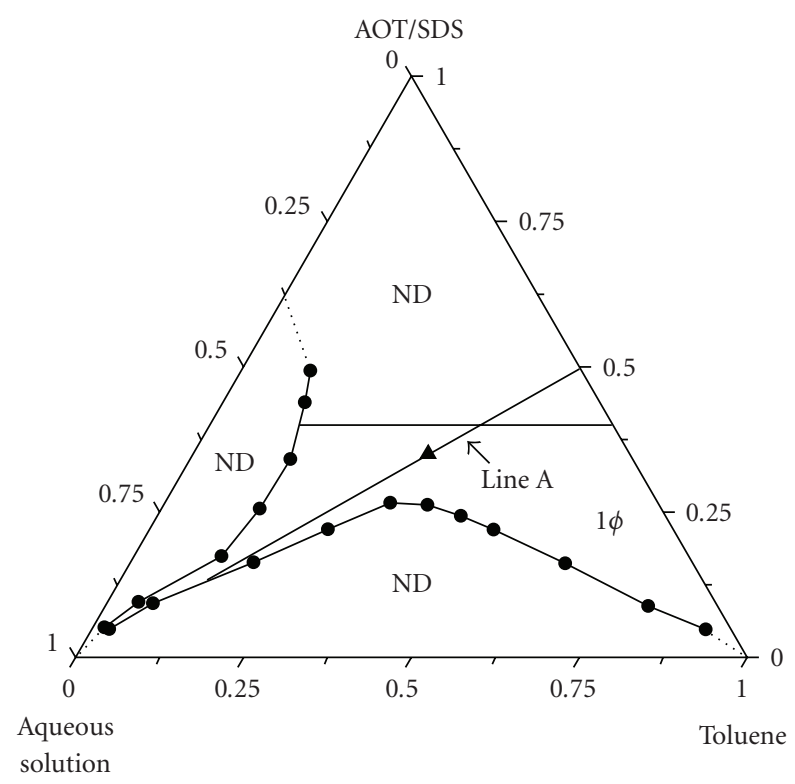

Figure 1: Partial phase diagram at $70^{\circ} \mathrm{C}$ of AOT/SDS $(2 / 1$, $\mathrm{w} / \mathrm{w}$ ), toluene and a $0.5 \mathrm{MAgNO}_{3}$ aqueous solution showing the microemulsion region $(1 \phi)$. The nondetermined regions (ND) were not examined because they are not interesting for the present work. Composition of the microemulsion where precipitation reactions were carried out is shown by $(\boldsymbol{\Delta})$. Line A indicates the constant surfactant/toluene weight ratio at which electrical conductivities were measured.

2.2. Phase Diagram Determinations. Microemulsion regions at $70^{\circ} \mathrm{C}$ were determined by titration with $0.5 \mathrm{M}$ aqueous solution of $\mathrm{AgNO}_{3}$ of surfactant (AOT/SDS, 2/1, $\mathrm{w} / \mathrm{w}) /$ toluene mixtures at the following weight ratios: $5 / 95$, $10 / 90,20 / 80,30 / 70,35 / 65,40 / 60,45 / 55$, and 55/45 and by titration with toluene of aqueous solution/surfactant mixtures with varying weight ratios: 5/95, 10/90, 20/80, 30/70, and 40/60. Then, samples with an $\mathrm{AgNO}_{3}$ aqueous solution or toluene content slightly higher and lower than the visually determined phase boundary were prepared by weighing each component and allowing each sample to reach equilibrium in a water bath at $70^{\circ} \mathrm{C}$ in order to determine the phase boundary more accurately. The one phase microemulsion region corresponds to transparent or translucent samples that do not exhibit birefringence when observed through cross polarizers.

2.3. Synthesis of Silver Particles. Precipitation reaction was carried out in duplicate at $70^{\circ} \mathrm{C}$ in a $100 \mathrm{~mL}$ jacketed glass reactor equipped with a reflux condenser and an inlet for the microemulsion and sodium borohydride aqueous solution feed. The microemulsion contained $30 \mathrm{wt} . \%$ surfactant, $30 \mathrm{wt} . \% 0.5 \mathrm{M} \mathrm{AgNO}_{3}$ aqueous solution, and $40 \mathrm{wt} . \%$ toluene. The procedure for the precipitation reaction started with loading the reactor with the microemulsion $(100 \mathrm{~g})$ and then raising temperature to $70^{\circ} \mathrm{C}$. Then, $2.9 \mathrm{M}$ aqueous solution of sodium borohydride (6.6 g) was dosed drop by drop in 110 minutes to the reactor. At these conditions, molar ratio sodium borohydride/silver nitrate was equal to

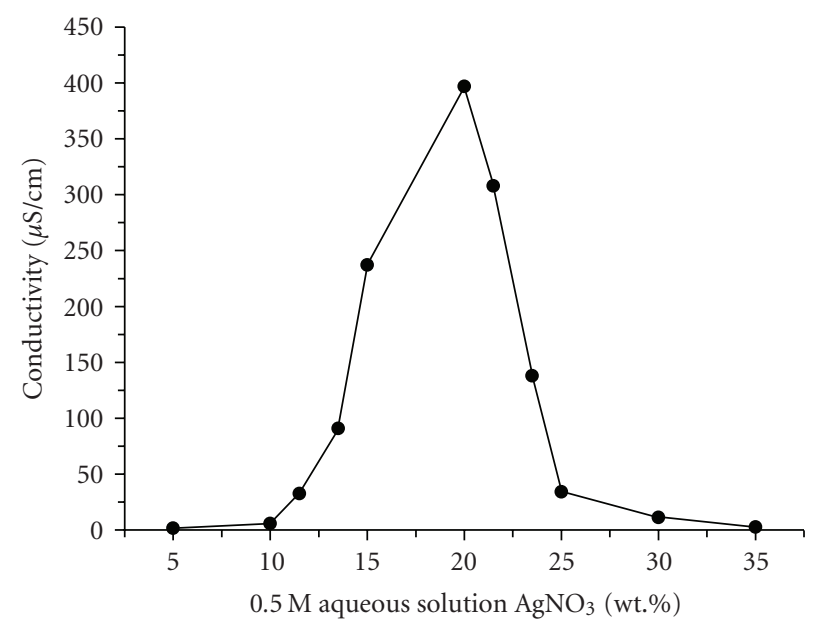

Figure 2: Electrical conductivities at $70^{\circ} \mathrm{C}$ of microemulsions at different concentrations of $0.5 \mathrm{M} \mathrm{AgNO}_{3}$ aqueous solution along the composition line A of Figure 1.

1.25 , that is, $25 \%$ higher than the stoichiometry ratio. After addition, completion reaction was allowed to proceed for 30 minutes and then acetone was added to precipitate the solids in the final reaction mixture. Afterwards, the precipitate was washed at least seven times with water-acetone $(81 / 19, \mathrm{w} / \mathrm{w})$ and then dried.

2.4. Characterization. Electrical conductivities were measured at $70^{\circ} \mathrm{C}$ and $1 \mathrm{KHz}$ with a Hach sension 5 conductivity meter. X-ray analyses were performed with a Siemens D-5000 X-ray Diffractometer. The silver content in final powder was determined by Atomic Absorption Spectroscopy in a Varian Spectra 250 AA equipment. Particle size was determined by High-Resolution Transmission Electron Microscopy (HRTME) in a Titan-300 kV. For these measurements, samples were prepared by dispersing the resulting powders in acetone with an ultrasonicator and then depositing the dispersion on a copper grid.

\section{Results and Discussion}

The phase diagram of the system made of AOT/SDS $(2 / 1, \mathrm{w} / \mathrm{w})$ mixture, toluene, and a $0.5 \mathrm{M} \mathrm{AgNO}_{3}$ aqueous solution is shown in Figure 1. It is noticeably that, as far as we know, a phase diagram of this system has not been previously reported in the specialized literature. A transparent region extends from the toluene-rich region to that rich in water, which widens the spectrum of compositions for further studies on precipitation in reverse microemulsions with high-water content or in bicontinuous microemulsions. To choose the microemulsion composition with high-water content to carry out precipitation reaction, electrical conductivities along the line A (weight ratio surfactant/toluene of 42.9/56.1) in the phase diagram were measured. Figure 2 shows the change of electrical conductivity with concentration of $0.5 \mathrm{M} \mathrm{AgNO}_{3}$ aqueous solution. At aqueous solution contents lower than $10 \mathrm{wt} . \%$, electrical 
conductivities are very low $(<5 \mu \mathrm{S} / \mathrm{cm})$. When the aqueous solution exceeds $10 \mathrm{wt} \%$, conductivities increase abruptly and reach a maximum around $400 \mu \mathrm{S} / \mathrm{cm}$ at $20 \mathrm{wt} . \%$. Then, conductivities decrease suddenly, diminishing to $11 \mu \mathrm{S} / \mathrm{cm}$ at $30 \mathrm{wt} . \%$ aqueous solution. These changes are due to the different capacities for conducting electrical current of different microstructures of microemulsions. Reverse microemulsions show low capacity for conducting electrical current because of their discontinuity $[19,20]$ while higher conducting capacity is observed in bicontinuous microemulsions as a result of having a continuous aqueous phase [20-23]. Determination of transition from reverse to bicontinuous microemulsions (or vice versa) based on the change of electrical conductivity as a function of aqueous phase content is a well-documented practice [24-28]. Based on conductivity behavior, it is concluded that bicontinuous microemulsions are formed along line A ranging from some point between 10 and $15 \mathrm{wt} . \%$ aqueous phase to some point between 21.5 and $25 \mathrm{wt} . \%$ aqueous phase. After this point, a transition from bicontinuous to reverse microemulsions occurs. This type of behavior has been previously reported in the literature for another system [29].

To carry out the precipitation reactions at highaqueous phase content, a reverse microemulsion with $30 \mathrm{wt} \%$ of $0.5 \mathrm{M} \mathrm{AgNO}_{3}$ aqueous solution and a molar ratio water/surfactant $(R)$ of 21 were chosen. The triangle in Figure 1 indicates the composition of the selected microemulsion. The appearance of precursor microemulsion is yellowish-translucent but it turns to black upon the starting addition of $\mathrm{NaBH}_{4}$ aqueous solution. After the end of reaction, the product was recovered obtaining $1.40 \mathrm{~g}$ in run1 , and $1.53 \mathrm{~g}$ in run-2, of grayish-black powder with $>99 \%$ silver content both as determined by atomic absorption spectroscopy. Figure 3 shows the X-ray diffraction pattern of samples of purified product from runs and the standard patterns of silver and $\mathrm{AgNO}_{3}$. The samples patterns show characteristic signals for the diffraction pattern of silver crystals, while there are not signals for $\mathrm{AgNO}_{3}$ crystals.

Low- and high-resolution TEM images of samples of runs are shown in Figure 4. High-resolution images reveal that particles are spherical in shape. Histograms obtained measuring over 550 particles for run-1 and over 400 for run-2 are also included in this figure. Particle size data in histograms allowed to calculate values of $8.6 \mathrm{~nm}$ in average diameter and $\sigma=2.9 \mathrm{~nm}$ for run-1. For run-2, 8.8 and $4.7 \mathrm{~nm}$ for average diameter and $\sigma$, respectively, were obtained. With basis on the high values of $R(21)$ and of $\mathrm{AgNO}_{3}$ concentration at which precipitation was carried out in this work, high particle size and wide particle size distribution (PSD) were expected. Different groups have found that particle size and PSD increase with $R$ in precipitation of silver nanoparticles in reverse microemulsions $[9,15,18]$. Zhang et al. [15] investigated the effect of $R$ on particle size and PSD in systems stabilized with AOT, and they found the highest values of average diameter $(5 \mathrm{~nm})$ and PSD $(\sigma=2.4 \mathrm{~nm})$ at the highest $R$ studied (15). Petit et al. [9] prepared silver nanoparticles by precipitation in reverse microemulsions stabilized with a mixture of AOT and the functionalized surfactant silver bis (2-ethylhexyl) sulfosuccinate [Ag(AOT)]

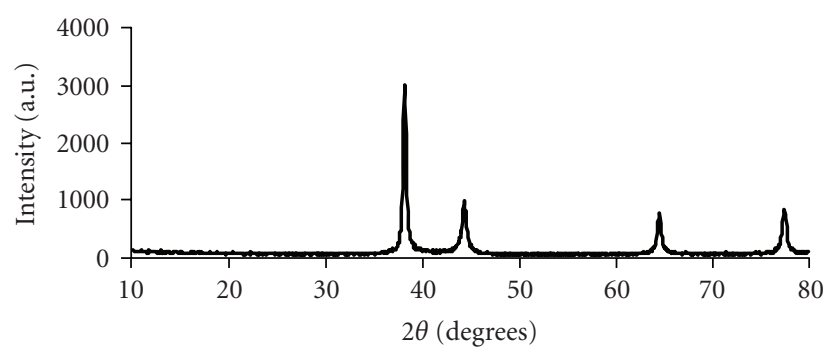

(a)

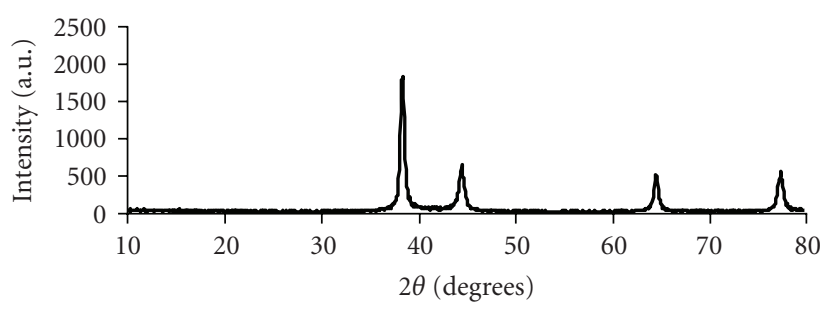

(b)

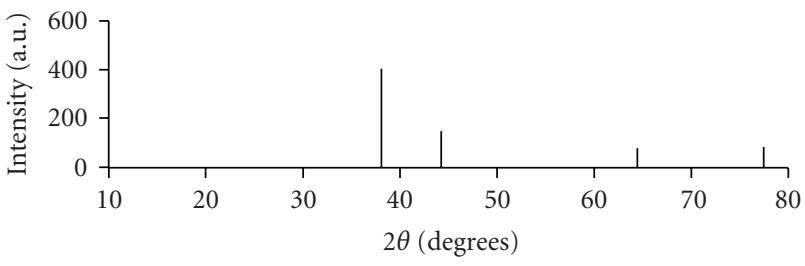

(c)

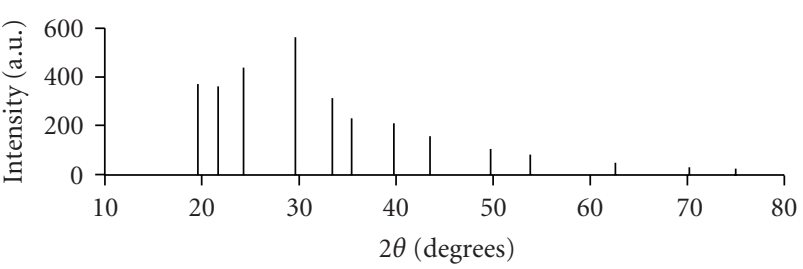

(d)

Figure 3: X-ray diffraction patterns for samples obtained in run1 (a) and run-2 (b) from precipitation at $70^{\circ} \mathrm{C}$ in a reverse microemulsion containing $30 \mathrm{wt} . \% \quad 0.5 \mathrm{M}$ aqueous solution of $\mathrm{AgNO}_{3}$ and $30 \mathrm{wt} . \%$ surfactant mixture. Standard patterns of silver (c) and $\mathrm{AgNO}_{3}$ (d) are included.

at different $R$ values. They determined a direct effect of $R$ on particle size and PSD, and found the largest particles (average diameter near to $7 \mathrm{~nm}$ ) and the widest PSD at $R=15$, that is, the highest value of the water/surfactant ratio used in the study. Zhang et al. [18] used reverse microemulsions prepared with SDS to precipitate silver nanoparticles, and they found an average diameter of $12.1 \mathrm{~nm}$ with a very wide PSD at $R=20$. An explanation for the direct effect of $R$ on particle size and PSD was proposed by Zhang et al. [30] and Husein and Nassar [31]. Zhang and coworkers mention that smaller micelles with a rigid surfactant layer are formed at low-water contents. These authors adduce that the high fraction of water bound by the surfactant molecules produces small nanoparticles with narrow PSD. At high-water contents, less and larger micelles are formed. 


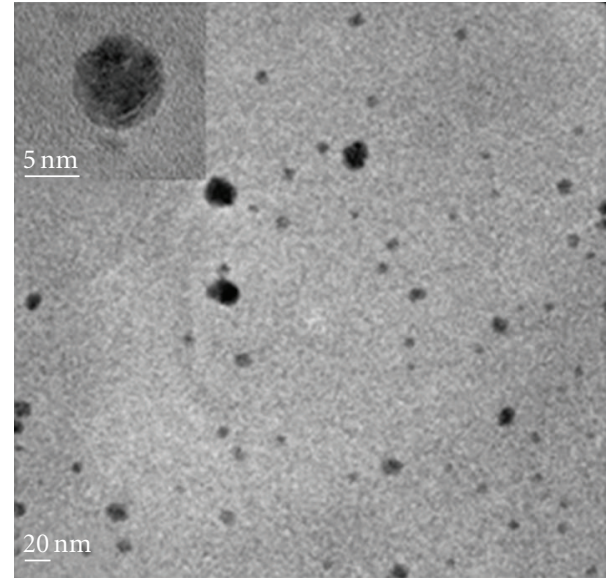

(a)

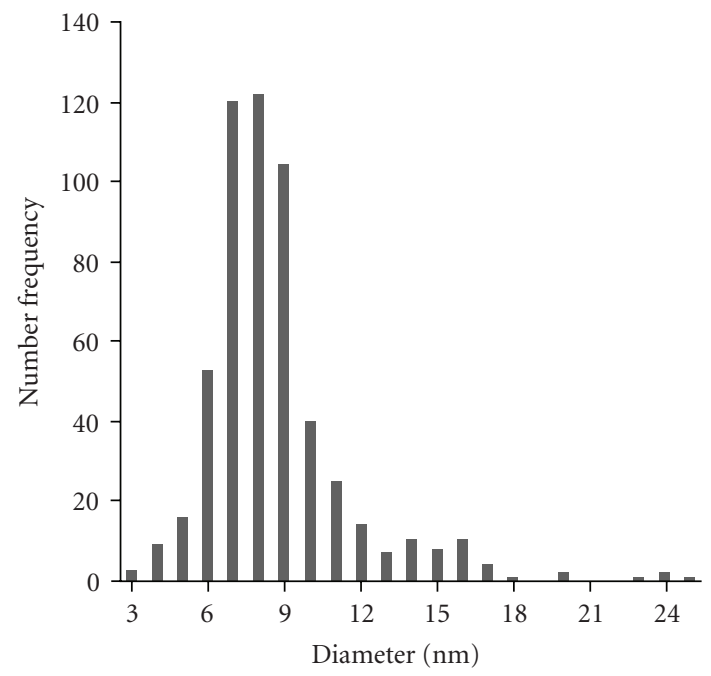

(c)

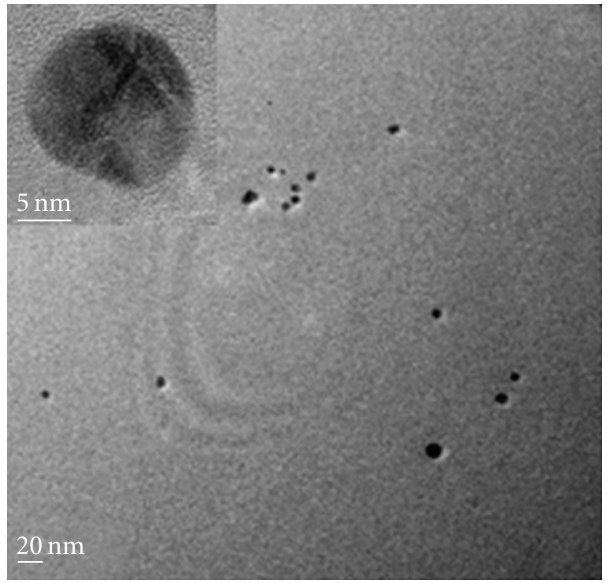

(b)

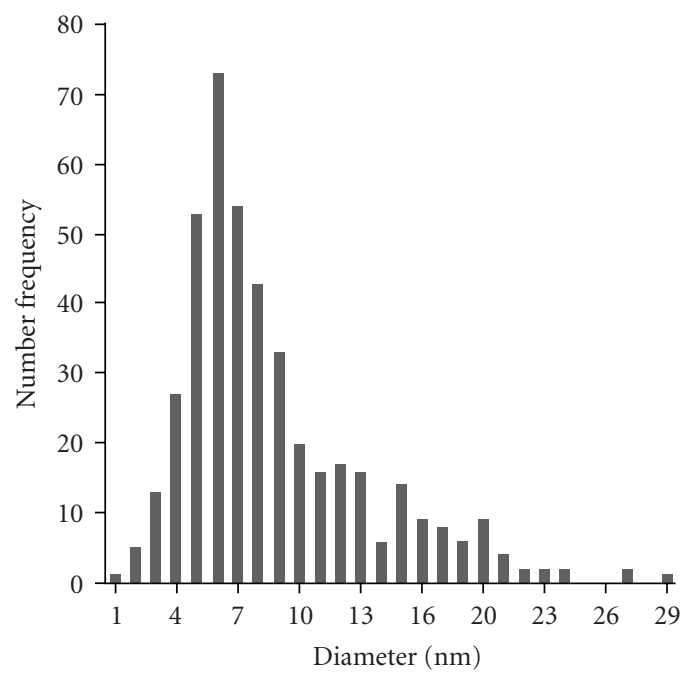

(d)

FIGURE 4: TEM micrographs and their histograms for particles obtained in run-1 (a, c) and run-2 (b, d) from precipitation at $70^{\circ} \mathrm{C}$ in a reverse microemulsion containing $30 \mathrm{wt} . \% 0.5 \mathrm{M}$ aqueous solution of $\mathrm{AgNO}_{3}$ and $30 \mathrm{wt} \%$ surfactant mixture. Insets show the corresponding high-resolution images of a silver particle.

At these conditions, surfactant layer at the micelles surface is more fluid because bound water turns into bulk water as water content increases. These conditions favor micellar interchange, which lead to larger and more polydisperse nanoparticles. On their point of view, Husein and Nasar [31] stress that decrease in rigidity of surfactant layer leads to an increase in the fraction of interparticle effective collisions, which contribute to particle aggregation.

According to Zhang et al. [15, 17], high $\mathrm{AgNO}_{3}$ concentrations lead to larger silver nanoparticles. These authors studied the precipitation of silver nanoparticles in reverse microemulsions prepared with AOT as surfactant and dodecane as the oil phase at different $\mathrm{AgNO}_{3}$ concentrations in the aqueous phase. They found an increase in particle size when $\mathrm{AgNO}_{3}$ concentration increased from 0.2 to $0.4 \mathrm{M}$. The authors argue that an increase in $\mathrm{AgNO}_{3}$ concentration promotes formation of a large number of tiny particles; however, this increases interparticle collision frequency. As a consequence, tiny particles aggregate into larger particles at high $\mathrm{AgNO}_{3}$ concentration.

Silver nanoparticles in our study were prepared at high values of $R$ and $\mathrm{AgNO}_{3}$ concentration. Furthermore, aqueous phase content used by us is much higher than those used in previous reports on precipitation of silver nanoparticles in reverse microemulsions [8-18]. In spite of this, the values of average particle diameter $(8.6$ and $8.8 \mathrm{~nm})$ and $\sigma(2.9$ and $4.7 \mathrm{~nm})$ obtained in this work are not too large. This could be the result of at least two characteristics of precipitation reaction in our study: dosing of aqueous solution of precipitating agent at the appropriate rate and use of toluene as the organic phase in microemulsion. The dosing rate used in this study, $0.06 \mathrm{~g} / \mathrm{min}$, was selected after a series of runs carried out at higher dosing rates, which rendered a mixture of a population of relatively small particles (average diameter $<10 \mathrm{~nm}$ ) with another of very large particles (average diameter $\gg 10 \mathrm{~nm}$ ) probably caused 
by temporal destabilization of microemulsion while added solution is accommodated, as appointed by Husein et al. [32]. This explanation is backed up by the observed decrease in the fraction of the very large particles population with the decrease in dosing rate of precipitating agent up to only small particles, at $0.06 \mathrm{~g} / \mathrm{min}$ dosing rate, were obtained. It is believed that slower addition of precipitating agent allows accommodation of aqueous solution in microemulsion without causing instability. On its hand, contribution of toluene to the obtained results could be explained as follows. Molecular volumes of some of the compounds usually used as organic phase in reverse microemulsions when studying silver nanoparticles precipitation were estimated using Spartan 04 V.1.0.1 software. The so-obtained values for cyclohexane, toluene, heptane, isooctane, octane, and decane were 112.2, 117.6, 144.0, 162.1, 162.5, and 199.3 $\AA^{3}$, respectively. It can be seen from here that molecular volume of toluene is one of the smallest. According to Cason et al. [33], this characteristic would allow to toluene molecule penetrating between surfactant tails, increasing rigidity of surfactant layer. In turns, this would give a better protection against aggregation during interparticle collisions.

Characterization of the products in this study indicates that $1.4 \mathrm{~g}$ in run-1 and $1.53 \mathrm{~g}$ in run-2 of silver nanoparticles (purity $>99 \%$ ) were obtained. Simple calculations based on the used recipe give an experimental yield of $1.3 \mathrm{~g}$ for run- 1 and $1.4 \mathrm{~g}$ for run-2 of silver nanoparticles per $100 \mathrm{~g}$ of reaction mixture, which is equivalent to 85.0 and $94.0 \%$ of theoretical yields, respectively. None of the reports on silver nanoparticles precipitation in reverse microemulsions found in our literature search shows the amounts of obtained silver nanoparticles neither experimental yields. However, most of these reports give data enough for calculating theoretical yields. Results of corresponding calculations show that the highest theoretical yield, $0.4 \mathrm{~g}$ per $100 \mathrm{~g}$ of reaction mixture [10], is much less than the experimental yield obtained in our study.

\section{Conclusions}

The precipitation reaction carried out in a reverse microemulsion containing high-aqueous phase concentration allowed obtaining silver nanoparticles with an average diameter of $8.6-8.8 \mathrm{~nm}$ and $2.9-4.7 \mathrm{~nm}$ in standard deviation. These values are less than those expected, considering the highmolar ratio water/surfactant and the high silver nitrate concentration used in the reaction. It is believed that slow dosing rate of aqueous solution of precipitating agent during the reaction and the use of toluene as the organic phase in microemulsion avoided particle aggregation. Furthermore, the experimental yield obtained in this study was much higher than theoretical yields calculated from reported data in the literature on precipitation of silver nanoparticles in reverse microemulsions.

\section{Acknowledgments}

CONACyT supported this research through grant SEP 2003CO2-45436. One of The authors (Y. D. Sosa) acknowledges a scholarship from CONACyT to pursue her MSc. works. The authors are grateful for Patricia Siller, Daniel Alvarado, and Alejandro Espinoza for their technical assistance.

\section{References}

[1] Royal Society, Royal Academy for Engineering, Nanoscience and Nanotechnologies: Opportunities and Uncertainties, chapter 2, The Royal Society, London, UK, 2004.

[2] Z.-Q. Tian, B. Ren, and D.-Y. Wu, "Surface-enhanced Raman scattering: from noble to transition metals and from rough surfaces to ordered nanostructures," Journal of Physical Chemistry B, vol. 106, no. 37, pp. 9463-9483, 2002.

[3] A. Campion and P. Kambhampati, "Surface-enhanced Raman scattering," Chemical Society Reviews, vol. 27, no. 4, pp. 241250, 1998.

[4] N. Pradhan, A. Pal, and T. Pal, "Silver nanoparticle catalyzed reduction of aromatic nitro compounds," Colloids and Surfaces A, vol. 196, no. 2-3, pp. 247-257, 2002.

[5] H. Nakatsuji, H. Nakai, K. Ikeda, and Y. Yamamoto, "Mechanism of the partial oxidation of ethylene on an Ag surface: dipped adcluster model study," Surface Science, vol. 384, no. 1-3, pp. 315-333, 1997.

[6] Q. L. Feng, J. Wu, G. Q. Chen, F. Z. Cui, T. N. Kim, and J. O. Kim, "A mechanistic study of the antibacterial effect of silver ions on Escherichia coli and Staphylococcus aureus," Journal of Biomedical Materials Research, vol. 52, no. 4, pp. 662-668, 2000.

[7] J.-W. Kim, J.-E. Lee, S.-J. Kim, et al., "Synthesis of silver/polymer colloidal composites from surface-functional porous polymer microspheres," Polymer, vol. 45, no. 14, pp. 4741-4747, 2004.

[8] P. Barnickel and A. Wokaun, "Synthesis of metal colloids in inverse microemulsions," Molecular Physics, vol. 69, no. 1, pp. 80-90, 1990.

[9] C. Petit, P. Lixon, and M.-P. Pileni, "In situ synthesis of silver nanocluster in AOT reverse micelles," Journal of Physical Chemistry, vol. 97, no. 49, pp. 12974-12983, 1993.

[10] L. A. Pavlyukhina, T. O. Zaikova, G. V. Odegova, S. A. Savintseva, and V. V. Boldyrev, "Silver clusters and nanoparticles: preparation in water-in-oil microemulsions and some physical properties," Inorganic Materials, vol. 34, no. 2, pp. 109-113, 1998.

[11] R. P. Bagwe and K. C. Khilar, "Effects of intermicellar exchange rate on the formation of silver nanoparticles in reverse microemulsions of AOT," Langmuir, vol. 16, no. 3, pp. 905910, 2000.

[12] Z. Zhang, R. C. Patel, R. Kothari, C. P. Johnson, S. E. Friberg, and P. A. Aikens, "Stable silver clusters and nanoparticles prepared in polyacrylate and inverse micellar solutions," Journal of Physical Chemistry B, vol. 104, no. 6, pp. 1176-1182, 2000.

[13] J. Zhang, B. Han, J. Liu, et al., "Recovery of silver nanoparticles synthesized in $\mathrm{AOT} / \mathrm{C}_{12} \mathrm{E}_{4}$ mixed reverse micelles by antisolvent $\mathrm{CO}_{2}$," Chemistry A, vol. 8, no. 17, pp. 3879-3883, 2002.

[14] M. Andersson, J. S. Pedersen, and A. E. C. Palmqvist, "Silver nanoparticle formation in microemulsions acting both as template and reducing agent," Langmuir, vol. 21, no. 24, pp. 11387-11396, 2005.

[15] W. Zhang, X. Qiao, J. Chen, and H. Wang, "Preparation of silver nanoparticles in water-in-oil AOT reverse micelles," Journal of Colloid and Interface Science, vol. 302, no. 1, pp. 370373, 2006. 
[16] W. Zhang, X. Qiao, and J. Chen, "Synthesis and characterization of silver nanoparticles in AOT microemulsion system," Chemical Physics, vol. 330, no. 3, pp. 495-500, 2006.

[17] W. Zhang, X. Qiao, and J. Chen, "Synthesis of nanosilver colloidal particles in water/oil microemulsion," Colloids and Surfaces A, vol. 299, no. 1-3, pp. 22-28, 2007.

[18] W. Zhang, X. Qiao, and J. Chen, "Formation of silver nanoparticles in SDS inverse microemulsions," Materials Chemistry and Physics, vol. 109, no. 2-3, pp. 411-416, 2008.

[19] H.-F. Eicke, M. Borkovec, and B. Das-Gupta, "Conductivity of water-in-oil microemulsions: a quantitative charge fluctuation model," Journal of Physical Chemistry, vol. 93, no. 1, pp. 314317, 1989.

[20] M. Borkovec, H.-F. Eicke, H. Hammerich, and B. Das-Gupta, "Two percolation processes in microemulsions," Journal of Physical Chemistry, vol. 92, no. 1, pp. 206-211, 1988.

[21] J. F. Billman and E. W. Kaler, "Structure and phase behavior in five-component microemulsions," Langmuir, vol. 6, no. 3, pp. 611-620, 1990.

[22] A. Maitra, C. Mathew, and M. Varshney, "Closed and open structure aggregates in microemulsions and mechanism of percolative conduction," Journal of Physical Chemistry, vol. 94, no. 13, pp. 5290-5292, 1990.

[23] A. V. Sineva, D. S. Ermolat'ev, and A. V. Pertsov, "Structural transformations in a water- $n$-octane + chloroform-sodium dodecyl sulfate- $n$-pentanol microemulsion," Colloid Journal, vol. 69, no. 1, pp. 89-94, 2007.

[24] L. M. Gan, T. H. Chieng, C. H. Chew, and S. C. Ng, "Microporous polymeric materials from microemulsion polymerization," Langmuir, vol. 10, no. 11, pp. 4022-4026, 1994.

[25] T. H. Chieng, L. M. Gan, C. H. Chew, et al., "Microporous polymeric materials by microemulsion polymerization: effect of surfactant concentration," Langmuir, vol. 11, no. 9, pp. 3321-3326, 1995.

[26] C. H. Chew, L. M. Gan, L. H. Ong, et al., "Bicontinuous structures of polymerized microemulsions: ${ }^{1} \mathrm{H}$ NMR selfdiffusion and conductivity studies," Langmuir, vol. 13, no. 11, pp. 2917-2921, 1997.

[27] J. Liu, L. M. Gan, C. H. Chew, W. K. Teo, and L. H. Gan, "Nanostructured polymeric materials from microemulsion polymerization using poly(ethylene oxide) macromonomer," Langmuir, vol. 13, no. 24, pp. 6421-6426, 1997.

[28] C. H. Chew, T. D. Li, L. H. Gan, C. H. Quek, and L. M. Gan, "Bicontinuous-nanostructured polymeric materials from microemulsion polymerization," Langmuir, vol. 14, no. 21, pp. 6068-6076, 1998.

[29] B. P. Lim, J. Wang, S. C. Ng, C. H. Chew, and L. M. Gan, "A bicontinuous microemulsion route to zinc oxide powder," Ceramics International, vol. 24, no. 3, pp. 205-209, 1998.

[30] W. Zhang, X. Qiao, and J. Chen, "Synthesis of silver nanoparticles-effects of concerned parameters in water/oil microemulsion," Materials Science and Engineering B, vol. 142, no. 1, pp. 1-15, 2007.

[31] M. M. Husein and N. N. Nassar, "Nanoparticle preparation using the single microemulsions scheme," Current Nanoscience, vol. 4, no. 4, pp. 370-380, 2008.

[32] M. Husein, E. Rodil, and J. H. Vera, "Formation of silver bromide precipitate of nanoparticles in a single microemulsion utilizing the surfactant counterion," Journal of Colloid and Interface Science, vol. 273, no. 2, pp. 426-434, 2004.

[33] J. P. Cason, M. E. Miller, J. B. Thompson, and C. B. Roberts, "Solvent effects on copper nanoparticle growth behavior in AOT reverse micelle systems," Journal of Physical Chemistry B, vol. 105, no. 12, pp. 2297-2302, 2001. 

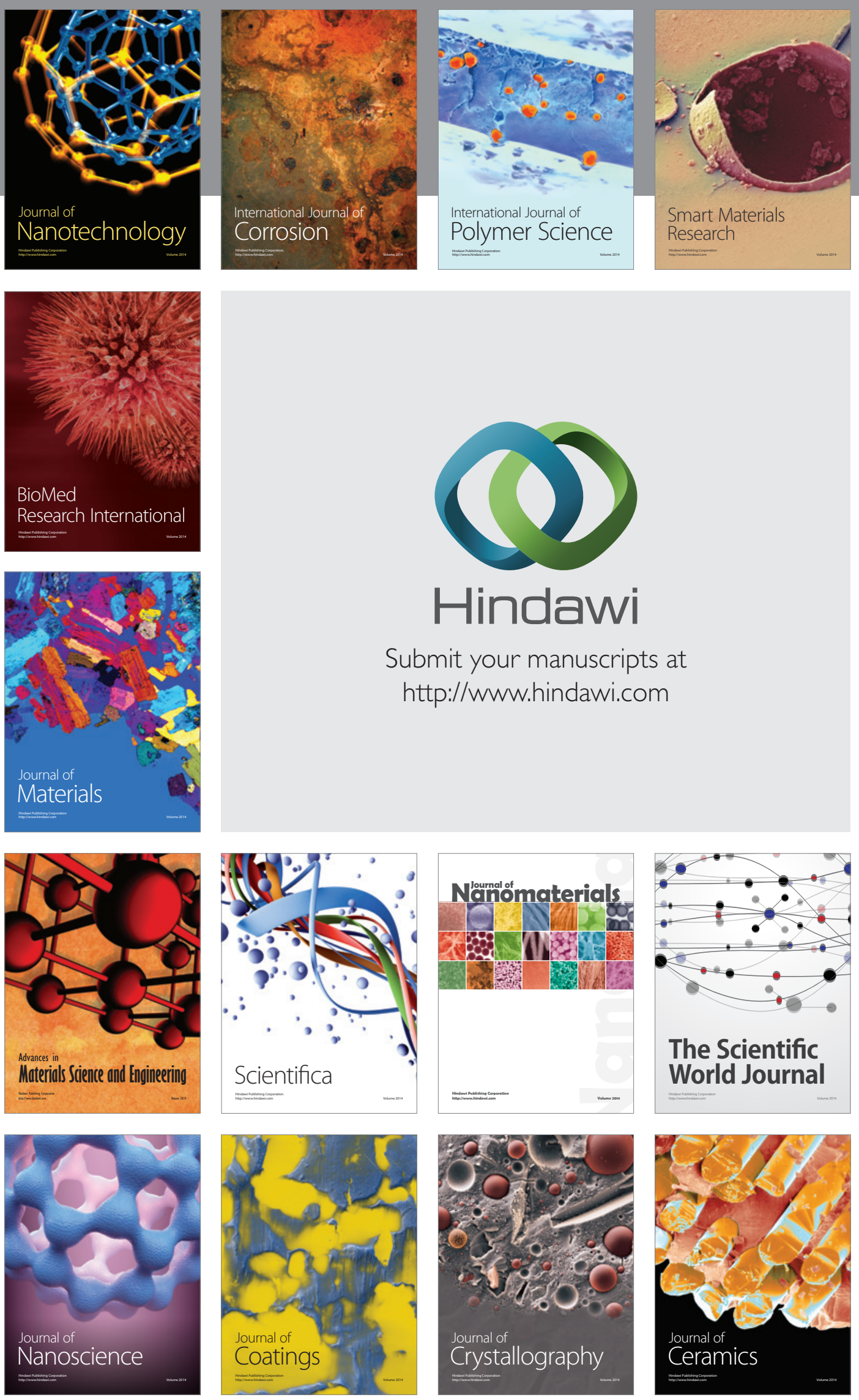

The Scientific World Journal

Submit your manuscripts at

http://www.hindawi.com

\section{World Journal}

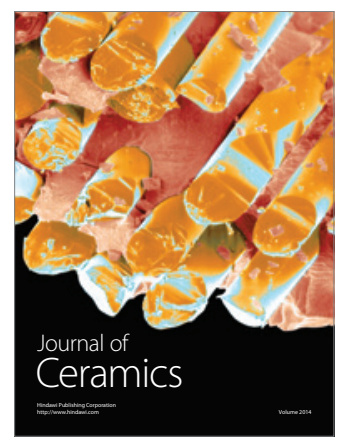

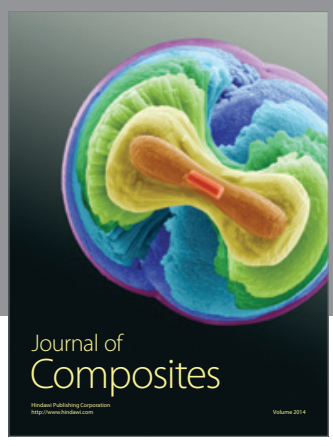
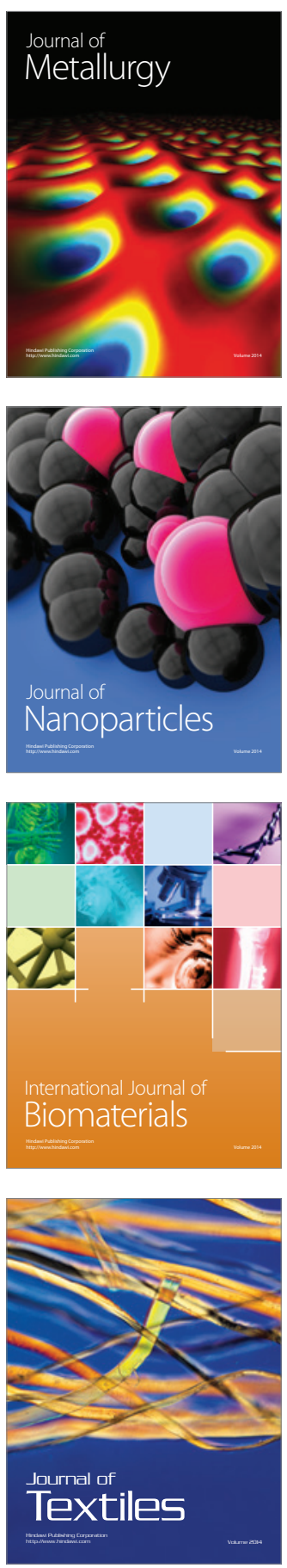